\title{
Desvelado el último secreto de la reina Marie-Antoinette*
}

\author{
Ana María IgLESIAS Botrán \\ Universidad de Valladolid \\ ana.botran@uva.es \\ http://orcid.org/0000-0002-9747-4047
}

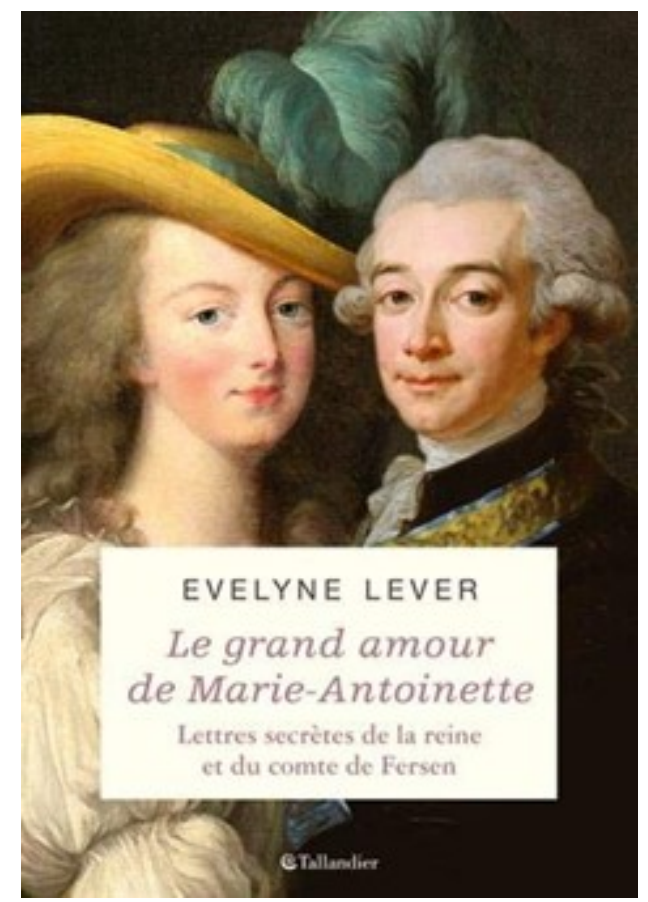

La última publicación de Evelyne Lever, Le grand amour de Marie-Antoniette. Lettres secrètes de la reine et du comte de Fersen (2020), es el resultado de un largo proceso de recopilación y análisis de las cartas que la reina Marie-Antoinette-Josèphe-Jeanne de Lorraine, consorte de Louis XVI, y el conde sueco Hans Axel de Fersen se enviaron desde junio de 1791 hasta casi el mismo momento de la muerte de María Antonieta en 1793. Este libro confirma con rigor científico que la reina y el conde se profesaban un profundo amor que duró años. Para llegar a esta conclusión, ha sido necesario un grupo multidisciplinar de expertos y la tecnología más puntera en rayos $\mathrm{X}$.

La autora de este libro, Evelyne Lever, es una de las más prolíficas investigadoras sobre la figura de la reina María Antonieta. Desarrolla sus investigaciones en el seno del CNRS como especialista del siglo XVIII y ha sido galardonada varias veces en su trayectoria. El más reciente reconocimiento ha sido en 2020 con el premio Guizot de la Academia Francesa por su publicación Paris sous la terreur (2019).

Sus investigaciones se basan en muchos casos en las cartas y diarios de los personajes históricos del siglo XVIII, a partir de los cuales establece los acontecimientos y los perfiles psicológicos de sus protagonistas, lo que le permite trazar una amplia

\footnotetext{
* Acerca del libro de Eveline Lever, Le grand amour de Marie-Antoniette. Lettres secrètes de la reine et du comte de Fersen. (Paris, Éditions Tallandier, col. «Histoire», 2020, 374 p. ISBN: 979-1021043046).
} 
panorámica de la época. En el conjunto de sus publicaciones podemos observar tres ejes de trabajo. El primero y más abundante es sobre María Antonieta (1991, 2000, 2005a, 2005b, 2006, 2007, 2008, 2020). En segundo lugar, están otros personajes de la época como Luis XVI (1985), el Barón de Breteuil (1992), Madame de Pompadour (2003), o los marqueses de Bombelles (2009). Como tercer tema se encuentran otros asuntos históricos transversales como el embrollo del collar (2004), crónicas de la corte de Versalles $(2012,2013)$ y un diccionario amoroso de las reinas (2017). Es, por lo tanto, una de las mayores especialistas sobre la época y, por eso, sus publicaciones han sido distribuidas por las más prestigiosas editoriales francesas en historia y cultura.

En esta monografía el protagonismo recae en un conjunto de cartas que fueron ocultadas durante décadas por los familiares del conde Axel de Fersen. Uno de sus sobrinos, el barón Rudolf Maurits de Klinckowström, publicó en 1877 los documentos de su antepasado. En ellos, algunos de los pasajes, frases y palabras albergaban información ilegible porque fueron literalmente tachados. Investigadores y periodistas solicitaron al barón los documentos originales, pero no los entregó alegando que los había quemado.

La sorpresa llega en 1982 cuando se descubre que las cartas no habían sido destruidas. Sus descendientes las pusieron en venta en Londres y fueron adquiridas por los Archivos nacionales de Francia. En 2014 se inicia una investigación colaborativa denominada proyecto REX: Recherches sur l'extraction et exploitation des tracés sousjacents dans les manuscrits anciens. En ella participan cuatro centros de investigación: los Archivos nacionales, la Fondation des Sciences du Patrimoine, el Centre de recherche sur la conservation y el laboratorio DYPAC de la Universidad de Versalles Saint-Quentin-en-Yvelines. Su objetivo es descifrar con tecnología de rayos X los misteriosos pasajes de las cartas que aún no se habían podido analizar (pp. 9-12, 241-242). Los resultados de esta investigación no han podido ver la luz hasta el año 2020, despejando por fin las incógnitas sobre la verdadera relación que mantuvo la última reina consorte de Francia con el conde Hans Axel de Fersen.

El trabajo de Evelyne Lever está dividido en cinco partes: un prólogo introductorio (pp. 13-14), el relato de la historia entre ambos narrado en once capítulos (pp. 15-231), un epílogo (pp. 233-239), un anexo con la transcripción de las cartas (pp. 241-372), y las referencias a las fuentes utilizadas. En el prólogo se relata el momento en que Fersen y la reina se conocieron. Fue el 20 de enero de 1774, durante un baile de máscaras en la Ópera de París. Fersen no la reconoció cuando se acercó a hablar con él; pero, inmediatamente después de que ella se fuera, supo que había estado charlando con la entonces delfina de Francia.

El relato de la historia de los protagonistas está construido con las cartas como hilo conductor. Ello es posible gracias a que Axel de Fersen llevaba un diario y un cuaderno de correspondencia donde anotaba todas las informaciones sobre sus intercambios epistolares, de modo que, aun no disponiendo de todas las cartas, se puede 
saber cuándo se escribieron. La narración se divide en dos partes: la primera, que va del capítulo 1 al 9; y la segunda, compuesta de los capítulos 10 y 11 .

A lo largo de los nueve primeros capítulos, se explica que estaban continuamente en contacto ya que los paquetes de correspondencia encontrados coinciden con las ausencias de Fersen de París o Versalles. Las cartas hablan de temas variados y no se hallan muestras de que existiera una relación más allá de la amistad. Sin embargo, en el capítulo 5 se dan claves para entender que los términos de la relación pudieron dar un giro. Destaca, sobre todo, la fecha del 15 de julio de 1783 en la que Fersen y María Antonieta tuvieron un encuentro en los aposentos de la reina en Versalles. Es significativo cómo a partir de este momento se extreman las precauciones. Desde esta fecha y hasta 1791 el diario de Fersen fue voluntariamente destruido y, además, el conde modifica en su libreta de correspondencia el nombre con el que se refiere a ella, anotando «Elle» o solo una «E». Poco después volvió a cambiarlo y lo registró con el nombre Joséphine (p. 95).

La segunda parte del relato histórico se describe en los dos últimos capítulos, que narran la convulsa situación política y social. Tras la huida de Varennes, en la que se agrava su soledad y la situación se vuelve más peligrosa, la reina comienza a manifestar sus sentimientos y a arriesgarse a decir por escrito lo que hasta entonces no aparecía en las cartas. No obstante, había que ser precavidos porque el correo podía ser fácilmente interceptado, por eso utilizaban un código secreto, a veces tinta transparente y muchos de los pasajes están tachados. Los investigadores han desvelado gracias a tecnología punta en rayos $\mathrm{X}$ lo que hay bajo las tachaduras y han descifrado aquello que se escribía codificado. Gracias a estos métodos novedosos, se aclaran las alusiones explícitas al amor que se profesaban y, a través de estas cartas, se confirma la existencia de un profundo amor entre ambos, tal y como refrenda el extracto siguiente:

Vous savez que vous n'en êtes plus le maître et que toute votre personne est tellement liée à mon existence que vous devez bien vous en occuper. Adieu, encore une fois, vous que j'aime et aimerait jusqu’à mon dernier soupir (p. 204).

El último encuentro de Fersen y María Antonieta fue el 13 de febrero de 1792 y se detalla en el capítulo 10. Interesa esta fecha también porque en el diario de Fersen estaba tachada una anotación sobre aquel día: «Resté là»: era la frase que escribía cuando tenía relaciones sexuales con una mujer. Evelyne Lever plantea que en la correspondencia sólo podría haber referencias amorosas y nunca se dirigirían el uno al otro en términos explícitamente eróticos, ya que no era propio de la aristocracia no libertina. Sin embargo, las pruebas aportadas señalan que habría algo más que amor sentimental y que, al menos en los momentos que se indican, pudo haber también relaciones sexuales (p. 207).

El epílogo se centra en la historia vital de Fersen tras la muerte de María Antonieta. Su tristeza y desesperación le llevan a buscar testimonios y reliquias sobre su 
amada reina y a conmemorar los días más dramáticos de su relación. Se puntualiza que el 19 de marzo de 1795 Fersen recibe el último mensaje de María Antonieta a través de su amiga la baronesa de Korff. Esta misiva póstuma es definitiva y confirma una vez más su amor: "Adieu, mon cœur est tout à vous» (pp. 235-236).

En este mismo epílogo se relata también el sombrío final de Axel de Fersen. La opinión pública de su país lo consideró sospechoso de haber envenenado a Christian Augusto de Augustenbourg, el joven heredero de la corona sueca. Con esta excusa, Axel de Fersen es linchado y brutalmente asesinado por una multitud en medio de la calle el día del funeral del malogrado príncipe, el 20 de junio de 1810. Sin embargo, la Corte suprema de Suecia verificó después que la causa de la muerte del príncipe Christian había sido un ataque de apoplejía. Esto supuso la absolución póstuma de Fersen y el reconocimiento del error con la celebración de un funeral oficial.

La última parte del libro está destinada a la reproducción de las cartas entre María Antonieta y Fersen desde el regreso de Varennes hasta la muerte de María Antonieta. Lo que se aporta aquí son los dobles mensajes que se enviaban. Se pueden leer los textos en los que comentan todo tipo de acontecimientos que les interesaban, pero también lo que estaba oculto. Disponemos por lo tanto del fragmento a la vista y, a continuación, se especifica el texto secreto que estaba debajo de los tachones. Están indicadas también las partes que no se han podido desvelar y las palabras ilegibles. Además, en las notas a pie de página se puntualizan las referencias necesarias para poder leer las cartas con todo su sentido, facilitando así la comprensión de las epístolas. Esta es la contribución más significativa de Lever, junto con el resultado de las investigaciones que le permiten adentrarse en el pensamiento de sus protagonistas, en sus anhelos, y lo que más interesa de este libro, descubrir el profundo amor que sentían el uno por el otro. La monografía termina con un listado de fuentes, dividida en manuscritas, impresas y una bibliografía seleccionada.

El trabajo de Evelyne Lever puede ser de interés para un amplio público. Constituye una contribución a la biografía de María Antonieta, a la resolución de algunas incógnitas sobre su visión de los acontecimientos que estaba viviendo, y desvela sus sentimientos amorosos más secretos. También aporta muchos datos sobre Axel de Fersen que fue, sin duda, una de las personas más importantes e influyentes de su vida. La exposición sencilla, ordenada, precisa y rigurosa del libro cumple una labor de divulgación que también puede interesar a los historiadores, a los especialistas en el siglo XVIII $\mathrm{y}$ a los francesistas en general.

\section{REFERENCIAS BIBLIOGRÁFICAS}

FERSEN, Axel von (1877): Le Comte de Fersen et la cour de France, extraits des papiers du grand maréchal de Suède, comte Jean Axel de Fersen. París, Firmin Didot. 
LEVER, Evelyne (1985): Louis XVI. París, Fayard.

LEVER, Evelyne (1991): Marie-Antoinette. París, Fayard.

LEVER, Evelyne (1992): Mémoires du baron de Breteuil. París, François Bourin, Julliard.

LEVER, Evelyne (2000): Marie-Antoinette, la dernière reine. París, Gallimard.

LEVER, Evelyne (2003): Madame de Pompadour. París, Perrin.

LEVER, Evelyne (2004): L'Affaire du Collier. París, Fayard.

LEVER, Evelyne (2005a): Marie-Antoinette. Journal d'une reine. París, Robert Laffont.

LEVER, Evelyne (2005b): Correspondance de Marie-Antoinette. París, Tallandier.

LEVER, Evelyne (2006): C'était Marie-Antoinette. París, Fayard.

LEVER, Evelyne (2007): Marie-Antoinette, un destin brisé. Paris, RMN.

LEVER, Evelyne (2008): Marie-Antoinette, Journal d'une reine. París, Robert Laffont.

LEVER, Evelyne (2009): Marquis et marquise de Bombelles, "Que je suis heureuse d'être ta femme ", Lettres intimes, 1778-1782. París, Tallandier.

LEVER, Evelyne (2012): Le Temps des illusions. Chronique de la Cour et de la Ville, 1715-1756. París, Fayard.

LeVer, Evelyne (2013): Chronique de la Cour et de la Ville, 1757-1789. París, Fayard.

LEVER, Evelyne (2017): Dictionnaire amoureux des reines. París, Plon.

LEVER, Evelyne (2019): Paris sous la terreur. París, Fayard. 